\title{
The many careers of negative polarity items
}

\author{
Regine Eckardt \\ University of Göttingen
}

\section{Part I: Traditional careers}

Negative polarity items are characterized by their restriction to negative contexts. Ladusaw (1979) proposed that for the most-discussed negative polarity items (NPIs), licensing contexts have to observe the semantic property of being downward entailing (see de Swart 1998, for an accessible introduction). According to a competing analysis, at least some NPIs undergo scalar licensing (Fauconnier 1975). While scalar approaches to NPI licensing have gained in popularity in recent years, there are undoubtedly many NPIs to which the approach cannot be applied. In the present article, I will take a diachronic perspective to discuss the function of scalar NPI licensing for various sub-classes of NPIs as well as for negative polarity sensitivity in general.

The scalar analysis of NPI licensing can derive the restriction to downward entailing contexts as an epiphenomenon of independent pragmatic mechanisms which are each attested independently: the capacity to evoke alternatives (ALT) and a scalar interpretation of alternatives 
(SCALE) which I will revisit in the first section. The analysis is corroborated by historical considerations. First, it can explain how speaker communities can ever agree to restrict the use of a word to a class of context that is characterized by a (contentless) semantic feature such as 'downward entailing'. Second, several new uses that develop out of NPI words and expressions arise by the loss, change or replacement of ALT or SCALE. I hence will defend the view that scalar NPIs are prototypical NPIs in that without this mechanism, the class of downward entailing contexts could not become cognitively accessible. However, there are clearly more ways in which a word or expression can become negative polarity sensitive. In the present paper, I will refer to three such classes:

- $\quad$ Escort particles (anche solo, auch nur, ook maar) which do not fall under the mechanism of scalar licensing themselves (as can easily be argued) but accompany scale-licensed material and therefore occur in downward entailing contexts.

- $\quad$ Analogy NPIs (squat, sikkepit), nonce words which adopt the meaning and restrictions of scalar NPIs with a transparent etymological origin.

- $\quad$ Mimicry NPIs with no ties to scalar elements at all (in die Tüte kommen 'go in my bag') which very often show more narrow restrictions to exclusively negative contexts. They are classed as strong or superstrong in the literature, and could lend themselves to an analysis as negative idioms. 
This is not meant to say that there might not be more subclasses that are worth being studied in their own right. However, the picture suggests that if a negative polarity item (of some kind) has an idiosyncratic range of licensing contexts, it does not have a recent history that ties it to a scalar expression.

Let me briefly comment on the distinction between weak and strong NPIs here, to avoid misunderstandings. I think that there are two kinds of NPIs that are classed as "strong" in the literature (i.e. restricted to antiadditive contexts; only used with negation words). For strong scalar NPIs (e.g. the much-discussed lift a finger in English), many speakers report that sentences which have them in weak licensing contexts are perhaps strange or marked, but by no means ungrammatical. ${ }^{1}$ There are, however, strong NPIs with no etymological or semantic ties to scalar licensing (e.g. German lange fackeln 'torch around for long'). Such NPIs are close to uninterpretable in weak licensing contexts. I will class the latter as mimicry NPIs which owe their restriction to anti-additive contexts to factors different from those that operate for scalar strong NPIs.

The paper is organized as follows. I will first review ALT and SCALE as ingredients of scalar NPI licensing and show how restriction to downward entailing contexts arises compositionally as an epiphenomenon of these factors. I will then discuss why scalar NPIs are often but by no

\footnotetext{
1 Including to one anonymous reviewer who ardently defended this intuition in his/her comments. I am glad to take these as a license to include this somewhat unorthodox confession into the main body of the paper.
} 
means necessarily words for small things or quantities ('minimizers'), and propose an analysis for scalar strong NPIs. We will then revisit new uses of NPIs which arise when ALT or SCALE are lost, or replaced by other pragmatic operators, and I will relate these changes to terms in grammaticalization theory like subjectification, bleaching or reanalysis. I will then turn to non-scalar NPIs, ordered by their remoteness to scalar NPIs: escort particles, NPIs by analogy, and mimicry NPIs. Particularly the latter will also frequently be NPIs with irregular distributions, i.e. strong, superstrong, or licensing contexts that seem to fit no known logical characterization at all.

\section{The ingredients of negative polarity sensitivity}

The scalar licensing analysis maintains that polarity sensitivity rests on two independent pragmatic ingredients, namely evoking alternatives (ALT) and emphatic scalar assertion (SCALE). The pragmatic process of evoking alternatives to a given utterance was first, and most extensively studied in focus semantics (Rooth $1985 ;$ 1992). Alternatives also play a prominent role in other pragmatic processes, for instance in the definition of Horn scales to derive scalar implicatures. Generally, possible alternatives to the given utterance often play a role in deriving the overall information content. Emphatic scalar assertions (SCALE) are a type of construction which rests 
on alternatives (Krifka 1995). The given utterance is compared in logical or probabilistic strength to its understood alternatives; the construction serves the purpose to highlight that a particularly strong, noteworthy, or surprising propositional content can truthfully be asserted. This is how a sentence $\mathrm{S}$ is interpreted as an emphatic scalar assertion:

1. Let $S$ be a sentence where some constituent $a$ is used emphatically. Speaker and hearer can relate the denotation of $a$ to alternatives in the space of meanings. ${ }^{2}$

2. Let $\operatorname{Alt}(S)$ be the set of propositions that arises if the meaning of $a$ is replaced in semantic composition by one of its alternatives.

A scalar interpretation $\operatorname{SCALE}(S)$ carries the following presupposition:

$$
p(\llbracket S \rrbracket)<p\left(s^{\prime}\right) \text { for all other alternatives } s^{\prime} \text { in } \operatorname{Alt}(S)
$$

where $p$ is a measure for the level of likelihood, unsurprisingness or salience of the contents of propositions (i.e. $\llbracket S \rrbracket$ is less likely, more surprising, less salient or whichever ordering relation makes most sense in a given case).

For instance, assume that a kid watches another one doing a jigsaw puzzle and remarks: That's an easy one. My baby BROTHER could do it. In

\footnotetext{
2 "Emphatically" normally will mean 'with an audible pitch accent' or 'in focus'. I want to leave it open, however, that the overall utterance can sometimes convey an emphatic use of $a$ even without further prosodic markers. Note that alternatives to the denotation of $a$ have to be of the same logical type as $a$.
} 
this case, the point in sentence two is twofold: The kid evokes alternatives to my baby brother, plausibly skilled persons like friend, mom, school teacher. And s/he signals that the utterance conveys the least likely in a range of alternative propositions which build on these alternatives.

My baby brother could do it. (least likely)

I could do it.

Mom could do it.

Our school teacher could do it. (all more likely)

This presupposition is met by the facts: Given what we expect about the readiness of different persons to do puzzles, it is indeed unsurprising to learn that a teacher can do it, but surprising that baby brothers can do it. Not all possible patterns give rise to coherent side messages. In the same situation, for instance, it would be incoherent for the kid to say: That's a difficult one. My baby BROTHER could not do it!. Talking about jigsaw puzzles, it is more likely that babies won't master them than that anyone more grown-up does not. Therefore, such an utterance would be pragmatically infelicitous, even though it is grammatically and logically innocent.

Scalar NPIs are characterized by the following lexical requirement: They always give rise to alternatives (ALT), and they have to occur in 
utterances which are interpreted as scalar emphatic assertions (SCALE). This is an example of how licensing is checked:

(1) I didn't sleep a wink.

(2) Lexical entry for $a$ wink:

denotes events of a very short duration: $\lambda \mathrm{e}[\tau(\mathrm{e})=\varepsilon]$ where $\varepsilon$ shorter than any lexicalized time span. (sortal restriction: restricted to sleeping, napping)

Potential to raise alternatives (ALT): $\operatorname{ALT}(a$ wink $)=\{\lambda \mathrm{e}[\tau(\mathrm{e})=\mathrm{z}] \mid$ longer time spans z $\}$

(3) I did not sleep a wink compares to I did not sleep five minutes I did not sleep quarter of an hour I did not sleep for one hour ...

SCALE requires that the proposition expressed is most surprising, most unlikely on the scale of available alternatives. In the present example, this follows due to the logical relations between alternatives. If I did not sleep a wink, this entails that I did not sleep five minutes either, nor a quarter of an hour, nor for one hour or anything longer. The logically strongest proposition is true in the least number of cases (or situations, or 
possible worlds). Therefore, the scalar requirement is met. The evaluation rests on logical forms for sentences of the following kind:

(4) SCALE [ I didn't sleep a wink ALT $]_{3}$

where ALT, like a focus operator, gives rise to the alternatives and SCALE effects the scalar presupposition (for other versions of the theory see Fauconnier (1975), Heim (1984), Krifka (1995), Chierchia (2006; 2004), Israel (1996), and Guerzoni (2004)).

ALT and SCALE, present by lexical requirement for scalar NPIs, are also available independently. In an early stage the word/phrase that later turns into an NPI can be used in scalar and normal constructions alike. The following use of a minute illustrates an ALT+SCALE use, even though contemporary English allows us to use minute in neutral contexts as well.

(5) I didn't sleep a MINUTE.

(6) Lexical entry for a minute: ${ }^{3}$

denotes events which take 1 minute: $\lambda \mathrm{e}[\tau(\mathrm{e})=1 \mathrm{~min}$.$] .$ emphatically focused:

\footnotetext{
${ }^{3}$ I will systematically use a simplified lexical entry that states the exact durations of events. Arguably, the 'at least' interpretation is more appropriate in general. However, all examples in this text would receive the 'exactly' reading by scalar strengthening anyway. Hence, the present analysis spares me extra steps in the semantic derivation and will help to keep matters clearer.
} 
$\operatorname{ALT}($ a minute $)=\{\lambda \mathrm{e}[\tau(\mathrm{e})=\mathrm{z}] \mid \mathrm{z}=5$ min., $\mathrm{z}=1$ hour, $\mathrm{z}=4$ hours, ... $\}$

(7) I did not sleep a minute

hence is presented against the background of alternative propositions like

I did not sleep five minutes

I did not sleep for an hour

I did not sleep for four hours ...

Visibly, not sleeping (even) a minute is less likely than all other negative statements.

What is the difference, then, between a neutral word like minute in an emphatic use like (5), and an NPI like wink in (1)? The emphatic statements, at least, are very similar. One difference between a minute in (5) and $a$ wink in (1) seems to be this: the former can be used emphatically, the latter has to (at least in the sense of denoting short durations for sleeping events). Constructions of this type, where the word occurs in the scope of negation, are described as 'emphatic negation' in the traditional literature on negation and Jespersen's Cycle. The analysis is suited to understand the early stages in Jespersen's pathway to negation, like Old French pas, point, mie, rien, and Old German/Old English wiht as well as other emphatic Old German negation particles drof, (nio) in Altere (see Jäger 2006[2008]: 68/69.). 
To summarize, a word $\alpha$ starts a career as a (scalar) negative polarity item if speakers adopt the following lexical specification:

1. Word $\alpha$ evokes alternatives ALT which need to be discharged.

2. Alternatives have to be discharged by a SCALE operator (with the above meaning). SCALE usually takes scope over the root sentence. ${ }^{4}$

Here are some commonly offered examples of alternatives for contemporary NPI:

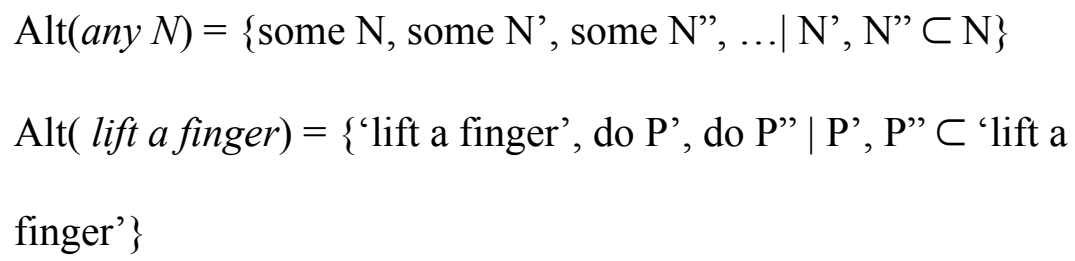

A negative polarity item is not licensed in a given context if the scalar presupposition is such that it can never hold true, like the misled example with baby brothers who cannot do jigsaw puzzles. ${ }^{5}$ The ungrammaticality of non-licensed NPIs in an utterance comes about because

\footnotetext{
4 SCALE may take lower scope in clearly quotational sentences. It may be excluded by higher restrictions on speech acts (see König 1977). I will not discuss examples which explore these exceptions here.

5 Earlier authors like Krifka argued carefully that this does not blur the distinction between contradictory sentences and ungrammatical sentences. Of course we can utter grammatically correct contradictions.
} 
the speaker consciously chose an expression with a certain pragmatic effect in a context where these pragmatic effects necessarily give rise to inconsistent presuppositions. It turns out that scalar licensing (ALT+SCALE) predicts licensing contexts which include all downward entailing contexts (the reader in need of examples is invited to check Huddleston \& Pullum (2002) for a broad range of licensing contexts). Scalar licensing is also suited to predict licensing in Strawson-entailing contexts (von Fintel 1999) as well as other problematic examples (Israel 1996). I take scalar NPIs to be 'prototypical' NPIs because their complex distribution is derived from cognitively accessible, independently attested pragmatic operations. We will later see what happens to an NPI if one or both these operations disappear or change.

\section{Headhunting: NPI candidates}

Which words and expressions do have the semantic potential to enter the initial emphatic constructions? The account is not inherently restricted to 'minimizers' or other terms of 'minimal value'. Terms that denote most general properties are also likely starting points (a living soul, eine Menschenseele) but generally, any expression which serves in a sentence to express a proposition which is less likely, more striking than anything else that could have been said in its stead could enter the road to NPI-hood. 
Consider the following made-up example for emphatic statements that might be heard at a tourist office in Paris.

(8) Anton was so stupid, he would not even see the Eiffel Tower.

(9) These German tourists are so disorganized, they do not even find the Eiffel Tower.

What is at stake here is whether people find or see certain things. In this situation, 'not being able to see the Eiffel Tower' is worse than 'not being able to see $X^{\prime}$ for smaller or less prominent $X$-s. The sheer size of the Eiffel Tower is exactly the reason why 'not even perceiving this thing' is so striking. Clearly, sentences (8) and (9) are well formed sentences in contemporary English and do not involve collocation, metaphor, idioms or other non-literal forms of meaning. However, speakers who encounter this worst case scenario with sufficient frequency might generalize the use of Eiffel Tower to other verbs when they want to express that nothing has been achieved. The following sentences toy with this attempt. ${ }^{6}$

(10) Harry is so stupid, he does not even understand Eiffel Tower.

(11) My granny is really deaf, she hardly hears Eiffel Tower.

\footnotetext{
${ }^{6}$ Such generalized uses seem to be immediately classed as degree adverbials, and not as transferred NP reference. This might be the reason that (10) and (11) sound much more convincing than their counterpart with a full DP the Eiffel Tower. Apparently, semantic generalizations which move a word into a new grammatical category come along with the requirement that the new item also 'looks like' other material in that category. In our case, adverbials that start with determiner the would just be too marked.
} 
To the extent that you are willing to understand such ad hoc innovations, you will have applied the well-known process of generalization. Importantly, what becomes more general is the range of verbs that can be combined with the phrase Eiffel Tower. It is not the semantic content itself that becomes more general - even though it changes dramatically. Actually, the meaning of Eiffel Tower changes from the singular property of being that famous building into an adverbial of minimal degree. One would not even claim that the former extension of the word is a subset of the new extension. ${ }^{7}$

The trade-off is, of course, that the pragmatic function of the new expression is more restricted. While Eiffel Tower in its older sense could occasionally be used in emphatic scalar assertions (see (8), (9)), the putative Eiffel Tower as in (10) and (11) would serve the function to exclusively be used in emphatic scalar assertions. We hence witness a gain-and-loss process of the kind that was first pointed out by König \& Traugott (1988). Although this is clearly an invented example, NPIs that rest on expressions for big things actually do exist: ${ }^{8}$ People won't do $x$ for all the rice in China, or talk about a place as Da bringen mich keine zehn Pferde rein. ('I won't enter even if ten horses drag me'; see Krifka 1995). Hence, scalar NPIs need not be minimizers which is why I generally will avoid this misnomer.

\footnotetext{
7 This is for reasons of ontological hygiene mainly. You would not want to have a property extension that contains an infinity of events, plus one tower.

${ }^{8}$ I want to thank an anonymous reviewer who brought up this expression.
} 
The scale-based analysis of items in the early NPI stage provides a correct mix of universal and culture dependent components to account for the fact that polarity sensitive items are frequently, though not necessarily, words that derive from minimizers. Possible origins of non-scalar NPIs will be reviewed in Sections 8 to 10 .

\section{First career choices: weak and strong scalar NPIs}

Much research in NPI-licensing addresses varying patterns of distribution for NPIs, like the weak-strong distinction. Weak NPIs are those like any and ever which can be found not only in the scope of negation, but also under only, every, in if-clauses, under rarely, few, and hardly. Strong NPIs, in contrast, are reported to be restricted to anti-additive contexts, which roughly means that they need a negation somewhere in the sentence. Expressions like (not) lift a finger and (not) care a damn are examples, but also (not) sleep a wink is reported to be of this kind. Interestingly, speakers' reactions to strong NPIs in weak licensing contexts diverge: Some find them just slightly awkward, some (including one reviewer of an earlier draft) find them fully acceptable, and some (including influential researchers on NPIs) classify examples as ungrammatical. I will propose an analysis for the weak-strong distinction which might also explain the variant judgments; details have been laid out in Eckardt (2005; 2008b). 
We have seen that words for things of small size or value are one likely source of NPIs. They serve to express that some action or activity took place to only a minimal extent. In some of these cases, we would even like to say that the action or activity has not really taken place at all, if nothing had happened except what is measured by that expression. Consider once more the quasi-temporal measure $a$ wink in sleep a wink. We cannot seriously conceive of a situation where somebody sleeps a wink's length but not longer. More formally, it is not possibly in a given situation that there exists an event $e$ of sleeping which is $a$ wink long without there being a superevent $E$ of sleeping which lasts longer. Similar situations of sub-atomic measure standards can be found in many domains: we cannot think of an event of working where someone lifts a finger and nothing more. We cannot think of evil persons where the vile character is evidenced by their hurting flies and nothing more. As little as we could think of one molecule of salami - even though, clearly, all salami consists of molecules eventually. In Eckardt (2008a) I argue that contexts which license weak NPIs but fail to license strong NPIs systematically give rise to a minimal achievement implicature. Let me illustrate this with a wink.

(12) ?*Few students slept a wink last night.

Hearers are prone to derive the following implicature: 
(13) The speaker is talking about at best few students. He chose to characterize them with the lowest possible achievement, namely 'sleeping a wink'. It would be relevant, or more interesting, to learn that few students slept $t$ time for some longer amount $t$ of time. The speaker refrained from asserting this. Hence, he must have reason not to. The reason must be that, in order to talk about few students, 'sleeping a wink' was the best achievement that could be attributed to that quantity of students. Any more substantial achievement would have applied to an even lesser number - for instance only one.

Hence there must have been at least some student who actually slept a wink and nothing more.

At this point, hearers' intuitions differ as to whether this is a reasonable message. For some, $a$ wink seems to denote a small, but reasonable quantity of sleeping. They would be able to use $a$ wink as in the following quote from a UK website. Apart from the fact that the writer seemed to be afflicted by a toothache, I have no reason to doubt his competence as a speaker of English.

(14) by evening $i$ had toothache, then at night $i$ hardly slept a wink due to pain 
Other speakers, however, use a wink in the 'molecular' sense in which it only applies to sleeping episodes that can only ever occur as parts of longer naps. These speakers will refute (12) and (14), and restrict the use of $a$ wink to anti-additive contexts.

Given that the lexical meaning of an NPI emerges by a process of meaning change from the lexical meaning of the preceding item, the resultant meaning is underdetermined to a certain degree. In an invisible hand choice, speaker communities decide whether the new word should be used as measuring out subminimal events, or as simple small-degree adverbs or most-general indefinites. What is remarkable is that this choice can be arbitrary to a certain extent. For instance, if we look at the distributions of negation particles in Old French (pas, mie, rien, point, goutte) we find that pas shows the typical distribution of a strong NPI while all others are attested in all NPI contexts, including those that are typical for weak NPIs (Eckardt 2003; 2006). What is remarkable here is that mie (earlier: 'crumb') and point (earlier: 'point') are as much minimizers as pas (earlier: 'step'). Yet, speakers of Old French for some reason decided that events of a mie or point extent were possible, whereas events of a pas extent were not. For this reason, the choice of becoming weak or strong is one made early in the development, it is not fully determined by the words older meaning, and it rests on the details of the lexical meaning that speaker communities collectively attribute to the emerging NPI. 
This concludes my discussion of the emergence of scalar polarity sensitive items. The next four sections will describe developments from this point on, where ALT or SCALE get lost, where new interpretations of alternatives are established, or semantic reanalysis takes place.

\section{Getting professional: bleaching}

When von der Gabelentz (1969[1901]: 241) wrote about bleaching ("verblassen"), he characterized this process as "loss of expressive force". 9 The passage covers changes from concrete to abstract meanings but also what we might call losses in rhetorical force. Today, we can distinguish more precisely between literal meaning, register, and presupposition. In this section, I will propose that NPIs can undergo a loss in presuppositional force and reach a stage where pragmatic licensing is transferred to syntactic licensing. The result are words that are best viewed as negation particles (see van der Auwera 2010).

According to the analysis in Sections 1 and 2, NPI licensing requires that two kinds of presuppositions are observed: the salience of alternatives which in turn feed the scalar presupposition. If we take a look into contemporary uses of polarity sensitive items for instance in English, it

\footnotetext{
9 "Was erst neu und selten war, wird dann alltäglich, und damit verliert es an Kraft, verblasst, rückt schliesslich wohl gar in the Reihe jener abstracten Bestandtheile der Rede, die es hat (...) ergänzen sollen (...).” (von der Gabelentz [2nd ed. 1901]1969: 241)
} 
turns out that not all uses occur in a context where alternatives and scalar statements are plausibly very salient. The following quote from an Agatha Christie novel exemplifies this observation. In the passage, the protagonist George Bartlett is interviewed by the police about his missing car. $\mathrm{He}$ speculates that the car might have disappeared because someone just drove off with it in an unattended moment.

(15) George Bartlett turned gratefully to the more placid voice. "Well, that's just it, you know. I mean, one can't tell, can one? I mean someone may just have buzzed off in it, not meaning any harm, if you know what I mean."

Agatha Christie, The Body in the Library.

The phrase not meaning any harm is used as a quotation by the protagonist. It is intended to refer to typical utterances of other persons where they want to emphasize their innocence. The passage does not address a question like how much harm did the thief mean? and does not offer salient alternative degrees of harm. However, any is still used in a sentence which in principle could be used to make an emphatic scalar statement.

With such examples, pragmatic requirements bleach into formal licensing requirements. A simple formal way to get rid of ALT and SCALE could be to replace the lexical requirement in Section 1 by the instruction 
"This item is to be used in downward-entailing ${ }^{10}$ contexts only" (following the theory proposed by Ladusaw 1979). The latter requirement needs neither alternatives nor scales. What we find more often, however, is that the loss of ALT or SCALE goes hand in hand with a simplification of the licensing contexts of that particular item. 'Bleached' licensing criteria are syntaxbased and more defined by a small number of allowed patterns of use. For instance, the presence of negation is a simple criterion that can easily be checked. As soon as an item's use is restricted to co-occurrence with negation, it has turned into a negation companion like pas for ne...pas, die Bohne in nicht die Bohne (German negation, literally 'not the bean'). Zeijlstra (2007) proposes to analyze such companions as cases of negative concord with overt or covert negation operators; I will not be able to review or evaluate all possible grammatical patterns and analyses here (see e.g. Linebarger 1987; Guerzoni 2006).

This stage has an interesting counterpart in language acquisition by children. In a study on the acquisition of NPIs by Dutch children, van der Wal (1996) observed in passing that the NPI verb hoeven ('(not) need to') was often used in unnegated sentences where the child wanted to express a negative proposition. She observes that these children evidently thought that hoeven alone was sufficient to express negation. Only later do children master the adult system and understand that hoeven needs to be licensed by

\footnotetext{
10 A set-denoting constituent $\mathrm{A}$ in some sentence $\mathrm{S}=\mathrm{XAY}$ is in a downward-entailing context iff the truth of sentence $\mathrm{S}$ (=XAY) entails the truth of XA'Y for all expressions $A^{\prime}$ which express a subset of $\mathrm{A}\left(\mathrm{A}^{\prime} \subseteq \mathrm{A}\right)$
} 
negation, rather than expressing negation. This amazing finding hence offers a case where early stages in language acquisition match late stages in language development, and it would be extremely interesting to see whether other NPIs, and also other languages, show similar acquisition stages.

In summary, when (scalar) NPIs are used too often without real pragmatic support or point, hearers/speakers understand that structural patterns rather than pragmatic function are what licenses the use of the item. The structural pattern is not fully determined by the earlier stage. Therefore, items after bleaching can show one of several possible distributions, ranging from NPI-like to negation particle, with an option to take over the function of negation altogether. They have then passed to a next stage. For those who work in diachronic linguistics, the moment of change is hard to detect, though, because each use of the item could in principle be licensed syntactically or semantically. The only exception are uses without negation (when the item changes to an expression of negation). The other kind of evidence standardly given for polarity sensitivity, judgments that a sentence is ungrammatical, are not available for historical stages.

\section{Career changes: subjectification}

In Section1, I proposed that two factors are at the basis of the source construction which feeds NPI careers: salient alternatives, and an emphatic 
scalar statement. These two factors were presented separately, and for good reason. Many languages possess polarity sensitive items which have a secondary use in positive (non-downward entailing) contexts. This use carries a pragmatic side message of non-specificity which, as I will show, rests on ALT but arises by making use of the alternatives in a different way. Let us start with some examples. Horn (2000) draws attention to the following use of any in English which is rare, and not covered by standard analyses of any.

(16) We need a doctor. Any doctor.

The second clause states that the kind of doctor is in no way restricted. Horn carefully argues that any in this example is not an NPI use (because a licensor is lacking), but neither is it an instance of free choice any (see Section 6), which would state that we need all doctors there are. Let me add a note of warning against descriptive labels for readings at this point. The example in (16) certainly gives rise to a free choice feeling, given that the sentence explicitly states that the choice of doctor does not matter. Such a feeling, however, is not the same as a semantic analysis. Free choice any occurs in places where the word simply has to denote a universal quantifier. Such uses motivate a semantic distinction between free choice any and existential any. However, if we analyzed any in (16) as a universal 
quantifier, we would predict that the sentence means 'we need every doctor'.

German possesses a similar item, irgendein. It has an NPI indefinite as well as an indiscriminative use which can systematically be distinguished by prosody. If irgend-is stressed, then it is polarity sensitive and has to occur in a licensing context. If irgend is unstressed, however, it is used in the indiscriminative use.

(17) Susanne hat jetzt irgendeinen neuen lover.

'Susanne has some new lover-whatsoever now'

(18) Wir brauchen irgendeinen Arzt.

'We need some doctor-whatsoever'

Indefinites of this type are currently investigated as epistemic indefinites. The exact meaning and pragmatics of epistemic indefinites seem to vary across languages (Condoravdi 2005; Menendez-Benito forthcoming; Falaus forthcoming for recent discussions). All analyses agree, however, that epistemic indefinites refer to different possible extensions of the head noun (e.g. lover, doctor). This can be viewed as a further development of the earlier ALT alternatives which are accessed as denotations of alternative nouns.

Different epistemic indefinites have slightly different ways in which the alternatives are pragmatically made sense of. Any doctor in (16) 
interacts with the modal need, probably such that our needs are fulfilled in all those possible worlds where some actual doctor is available, as well as in all those possible worlds where some counterfactual doctor is available (Dayal 1998). German irgendein has a slightly different way to interpret alternative extensions: in a positive sentence like (17), the speaker alludes to more specific descriptions of that new lover of Susan's, e.g. \{some new Latin lover, some new millionaire lover, some new and attractive lover, ... $\}$. The speaker can thereby signal that s/he intends to flout Grice's maxim of Quantity: 'You might want to know more, but you need not'. Similar ways to discharge alternatives are proposed in Chierchia (2006) for Italian $u n N$ qualsiasi ('some $\mathrm{N}$ whatever'). Chierchia's analysis is close in spirit to the present perspective in that he proposes a full tool kit of ALT operations and dischargers to analyze various Italian and English NPIs, epistemic indefinites, and free choice items. He does not, however, consider the historical dimension.

I see two reasons to assume that epistemic indefinites develop from NPIs. First, the English indiscriminative reading of any is rarer than NPI any and is still in need of discourse support. Note that (16) without the initial indefinite a doctor would sound very awkward. In the words of Gabelentz, (1969[1901]: 241) uses of indiscriminative any still carry full “expressive force". Second, the German NPI irgend is the stressed item of the two, whereas indiscriminative irgend is unstressed. In German, there is a full series of particles where in each case, stress goes with the older use and 
unstressed uses are younger. In terms of meaning, the change is characterized by the fact that a formerly unique way to interpret salient alternatives has been complemented by other ways to interpret these alternatives. In the older stage, only few syntactic contexts were suited for the resulting construction, the new stage allows uses in more kinds of sentences. I listed the non-specificity items under the heading of subjectification because the new side meanings often offer information about the epistemic state of the speaker and her communicative intentions.

\section{More career changers: reanalysis}

In this section, we will take a look the so-called free choice reading of existential NPIs.

(19) Sue can solve any problem.

The word any in (19) is used in the sense of every, not in the sense of some. A simple test for universal readings consists in combining any with the degree adverbs almost or absolutely, which is acceptable in (19). Only universal quantifiers can semantically combine with these, as the following examples show. 
(20) Sue can solve almost/absolutely every problem.

(21) *Sue can solve almost/absolutely some problem.

Attempts to combine almost or absolutely with indefinite any lead to unacceptable examples. This can help to distinguish indefinite from free choice readings.

(22) Nobody had (*almost)/(*absolutely) any question.

Different proposals have been made in the literature as to how free choice any should be semantically represented (Kadmon \& Landman 1993; Dayal 1998; Jayez \& Tovena 2003; Chierchia 2006; Menendez-Benito 2006; forthcoming; Giannakidou 2001). All proposals agree, however, that the denotation still involves ALT but does not make use of SCALE. Chierchia (2006) proposes that free choice any still denotes an existential quantifier ('some') which is, however, evaluated relative to varying domains of quantification (ALT) and hence leads to a universal statement. Dayal (1998) in contrast assumes the presence of a universal quantifier but again refers to alternative domains of quantification to derive the free choice effect. The core idea of her, and later analyses, consists in the proposal that modal contexts allow for variation over possible worlds. With this variation, the speaker can express that even if the extension of the noun $N$ in any $N$ had been larger, comprised more elements, the statement would still be true. 
This idea can be illustrated on basis of (23) which spells out the modal side message.

(23) Sue can solve any problem.

Sue has the potential to solve all actual problems.

Sue would also have the potential to solve more problems, if they'd turn up.

This is not the place to compare all analyses in detail. I would like to point out a few observations that simply show what possible roads may lead to universal readings. The first observation supports the view that not everything that looks like a universal quantification must necessarily be one. While English any has a free choice reading, its German counterpart irgend does not. Interestingly, certain comparative statements are expressed with free choice any in English while the translation equivalents (as equivalent as they can be) in German use NPI irgend:

(24) Tim is taller than any other student.

free choice: $\sqrt{ }$ taller than absolutely any other, taller than almost any other

(25) Tim ist größer als irgendein anderer Student.

'Tim is taller than irgendein other student' 
indefinite: *größer als fast irgendein anderer (*almost any)

*größer als absolut irgendein anderer Student. (*absolutely any)

The modification tests confirms that English uses a universal where German uses an existential. German irgend does not have a free choice reading as yet. Nevertheless, (24) and (25) mean the same. Such examples favor the hypothesis that semantic reanalysis (from the composition steps like (25) to composition like in (24)) gives rise to universal readings. Some German speakers might already see this option, too. The following anecdotal example, appeared in the Editorial of the DB-Magazin (journal in the Deutsche Bundesbahn) in April 2006.

(26) Die Mozart-Souvenirs findet man überall und irgendwo. the Mozart souvenirs finds one everywhere and anywhere

'You can find Mozart souvenirs anywhere and everywhere.'

It is now time to track the reanalysis in more detail. The logical equivalence of two semantic structures granted, it is still open what readers make of the salient alternatives that would come along with the traditional, existential interpretation. Interestingly, the alternatives do not just simply bleach away (which in this case would be tantamount to 'be forgotten') but remain part of the semantic/pragmatic content of any in the free choice 
reading. Reference to salient alternatives is maintained after reanalysis. Salient alternatives are exploited in modal contexts to yield the free choice whatever might turn up side message. Short-cutting the details of semantic analyses, we could characterize free choice readings as resting on ALT $+\forall$ (universal quantification).

\section{7. ... and bleaching, again}

Free choice universal quantifiers are quantifiers with the pragmatic potential to refer to alternatives; specifically to wider and narrower domains of quantification. Domain widening is usually exploited in modal variation which comes up for the restriction of free choice universal quantifiers to modal contexts.

As noted earlier, the pragmatic requirement to refer to alternatives can get lost over time. What remains in such a case is an ordinary universal quantifier. Haspelmath (1995) lists other sources of universal quantifiers but those which derive from free choice items and, eventually, polarity sensitive items are often revealed by their morphological parts. Hence, German jeder contains the polarity item $j e$ as a morpheme (though certainly no longer as a semantic part). It can be used in universal statements without modal character. The corresponding attempt to express the same content with a free choice item in English is ungrammatical. 
(27) Jeder im Raum hattedas Gespenst gesehen.

everyone in.the room had the ghost seen

'everyone in the room had seen the ghost'

(28) *Anybody in the room had seen the ghost.

It remains to be pointed out that even German jeder shows fossilized uses in at least a free choice sense, if not the old indefinite sense. ${ }^{11}$ They are restricted to the scope of ohne ('without') and are used to point out that an action with $N N$ ('with a tool') would have been more likely.

(29) Harry öffnete den Safe ohne jedes Hilfsmittel.

Harry opened the safe without FC-any tool 'Harry opened the safe without 'jedes (any)' tool.'

A sentence like (29) cannot convey that Harry failed to use all tools but possibly used some of them. In fact, the parallel versions with polarity sensitive indefinites are synonymous to (29) in content and pragmatic undertone.

(30) Harry opened the safe without (*absolutely) any tools.

Harry öffnete den Safe ohne irgendein Hilfsmittel.

${ }^{11}$ I owe this observation to Manfred Krifka (p.c.) 
Pragmatically neutral universal quantification constitutes an endpoint in the careers of polarity sensitive items. It arises when a former free choice item adopts a new lexical entry where it still denotes a universal quantifier but no longer refers to alternatives ALT. The following table summarizes the careers discussed so far.

$<$ TABLE 1 ABOUT HERE $>$

\section{Part II: Alternative Careers}

The first part of the paper described developmental pathways for scalar negative polarity items. I will now turn to polarity sensitive items which cannot plausibly be subject to scalar licensing. Are there other ways to create words with restricted contexts of use? What is the logic underlying these restrictions? How do they relate to the analyses for NPIs in part I? In the following sections, I will explore three kinds of items, namely scalar particles with an NPI distribution, snars NPIs and a class that I will call mimicry NPIs.

\section{Escort service: scalar particles with NPI distribution}


The particle auch nur in German is an NPI, like similar particles in other languages e.g. Italian anche solo. Clearly, the particle itself does not give rise to alternatives which would be evaluated against a SCALE operator. Hence, it is not an NPI such as those discussed in Section 1. However, it associates with a sister constituent $\alpha$ and signals that $\alpha$ gives rise to alternatives which are supposed to be interpreted by a SCALE operator with sentence wide scope. In addition, auch nur requires that the alternatives of $\alpha$, together with $\alpha$, are themselves ordered on a scale, and that $\alpha$ is at a comparatively low position of that scale. That auch nur is more than just an indicator of the presence of a hidden SCALE ('even') operator can be seen when we look at examples where an overt even statement does not have an auch nur counterpart:

(31) Sogar jeder, der eine EINS geschrieben hat, bekommt Nachhilfe. 'Even everyone who A-ced gets extra lessons.'

(32) *Jeder, der auch nur eine EINS geschrieben hat, bekommt Nachhilfe.

‘*Everyone who even A-ced gets extra lessons.'

(Unlike the German sentence, the English counterpart has a reading with positive even according to which only those who managed to write an A get extra lessons. If the German example were synonymous with (32), it would mean 'everyone, even those who got an A, got extra lessons'.) 
Different distributions of sogar and auch nur moreover indicate that auch nur restricts the kind of scale. For instance, if the sister constituent of auch nur is of type $(e, t)$, the only permissible ordering is the one where supersets rank lower than subsets: the more general a property, the less it counts on this scale. If the reverse ordering were possible, the following example should be acceptable.

(33) Hans war sogar/*auch nur unter den ersten Drei.

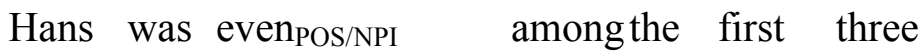

As a result, particles like auch nur are specifically tied to scalar statements where the scale bearing element - and therefore also its sister constituent auch nur - occurs in a downward entailing context. The etymology of auch nur, anche solo suggests a specialization of generally available nur ('only') and auch ('also', with an 'even' flavour) statements.

(34) Niemand hat auchnur einen Bleistift dabei. nobody had also only a pencil with-him Also: 'Nobody has only/at least a pencil.'

in the sense that in addition to other, higher achievements, even the least effort, the one of carrying a pencil, was not taken by anybody. Particles like auch nur, even though not looking back to a 'traditional NPI career', are 
closely linked to scalar NPI licensing in that their presence indicates that their sister constituent is subject to scalar NPI licensing. It is for this reason that escort particles share the NPI distribution of their sister constituents.

Let me briefly mention that auch nur can occur in all downward entailing contexts except under sentential negation where einmal is strongly preferred. German has two scalar NPI particles: (nicht) einmal ${ }_{\mathrm{NPI}}$ and auch nur $_{\text {NPI. }}$ The two together share the distributional restrictions of weak NPIs but divide up contexts so as to give rise to a so-called "bagel constellation"

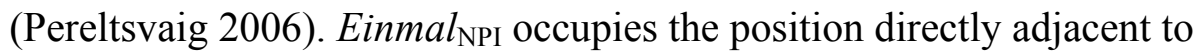
negation (a superstrong context in terms of Zwarts 1998) while auch nur $\mathrm{NPI}$ is allowed in all other NPI licensing contexts.

The starting context of einmal ${ }_{\mathrm{NPI}}$ in emphatic assertions of the type nicht einmal ('not even ONCE') is absolutely canonical. However, einmal $_{\mathrm{NPI}}$ could apparently not be extended to other contexts because the reanalyzed auch nur $_{\mathrm{NPI}}$ was already established in such contexts.

(35) Niemand hat auch nur/*einmal ${ }_{\mathrm{NPI}}$ gehustet. nobody has even/even coughed 'nobody even coughed.'

(36) Anne hat nicht *auch ur $_{\mathrm{NPI}} /$ einmal $_{\mathrm{NPI}}$ gehustet. Anne has not even/even coughed 'Anne did not even cough.' 
Auch nur, in turn, could not spread to the position directly adjacent to negation because this position was already conventionally inhabited by einmal $_{N P I}$. The blocking mechanisms that drive such developments need yet to be explored. Pereltsvaig (2006) proposes a mechanism of morphological blocking, which opens up interesting transmodular perspectives on the forces that drive language change.

\section{Analogy: snars NPIs in Dutch}

The following series of polarity sensitive items was reported to me by native speakers of Dutch. ${ }^{12}$ The items share the distribution of weak NPIs, but some are nonce-words without literal meanings, and speakers agree that the list could potentially be extended by more nonce-words. I list examples here.

(37) Hijheeft er geen snars van begrepen he has it no 'snars' of understood 'he has not understood one bit'

12 See Hoeksema 2002, 2010a, 2010b. I also want to thank Janneke Huitink and Paul Dekker for valuable input. 
What is crucial here is that snars does not seem to draw on any earlier literal meaning. Other items do, but the earlier meaning would require very special contexts to be used in a transparent scalar statement. It may be interesting to note that the only word which does not follow the informants' folk intuition "that it works best with (nonce) words that are monosyllabic" could in fact have productively derived from minimizing 'goat shit'.

(38) Hij heeft er geen hol ('hole') van begrepen $\operatorname{drol}$ ('turd') zak ('bag') reet ('ass') bal ('ball') sikkepit ('goat shit', though not transparent to speakers)

I refrain from testing a comprehensive paradigm of contexts for each one of these, but the following examples illustrate uses with a negative quantifier, and in the restrictor of a conditional.

(39) Niemand heeft er een snars van begrepen. nobody has it a 'snars' of understood (40) Als je er ook maar een snars van begrepen had, had je dit niet gezegd. 
'If you had understood even a 'snars' of it, you would not have said this'

The use of escort ook maar (Dutch NPI 'even') is reported to be obligatory. I have argued above that escort particles indicate that the speaker makes an NPI like scalar statement. Hence, escort particles help the speaker to express, and the hearer to understand, that these nonce words are intended to denote small measures. The items in question seem to be established by pure analogy with existing NPIs, simply copying the denotation and pragmatic requirements of existing NPIs.

Interestingly, these examples evidence that speakers are willing to adopt new words which are fully synonymous to older ones. It can be speculated that the novelty of such coinages as such adds to the "expressive force" of an utterance (and likewise that fecal expressions are sometimes particularly suited for exactly this reason).

\section{NPI mimicry}

In this final section, I will list some examples of NPIs which

- do not have any link to scalar assertions (synchronically or diachronically)

- $\quad$ have narrow or irregular ranges of licensing contexts. 
Such examples suggest that the ALT+SCALE construction is the only one that reliably singles out downward entailing contexts. Other items with a limitation to negative contexts either are restricted to simpler ranges of contexts (see the sections on bleaching above) or contexts that cannot be characterized by a simple semantic or pragmatic property.

In the literature, German brauchen in the sense of 'must' is listed as a negative polarity item. Dutch hoeven can be used in similar ways. The 'obligation' meaning is only available under negation.

(41) Niemand braucht zu kommen. nobody needs to come 'nobody has the obligation to come'

(42) *Peter braucht zu kommen. Peter needs to come unavailable: 'Peter must come'

In positive contexts, brauchen means 'need to have' and takes an NP object argument; infinitival complements are only possible in the NPI 'must' use. The Deutsche Wörterbuch (DW) lists NPI brauchen as a separate entry and reports earliest attested uses in the 18th century. We can therefore be sure that the NPI use does not derive from some old, obsolete sense of brauchen. Let us explore the potential of 'must' to enter in scalar statements. The NPI brauchen ('must') cannot give rise to scalar statements 
in its NPI uses, because there are no accessible alternatives which are logically narrower than 'must' and against which a scalar assertion can be construed. Note that dürfen ('may'), the second modal, has a wider extension than 'must' and is therefore not suited as an alternative in NPI licensing. ${ }^{13}$ Therefore, speakers cannot use ALT+SCALE to define the licensing contexts of brauchen ('must'). Could the verb in the older 'need' sense enter in an ALT+SCALE construction? In principle yes, as illustrated in the pair in (43).

(43) Peter does not have a car.

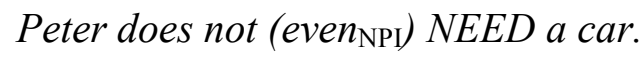

However, this contrast would highlight the possession aspect of older brauchen ('need') and it is highly unlikely that from such constructions, the narrower 'must possess' could generalize to 'must (do)'. Let me mention that the authors of DW assume that the development started via an impersonal obligation construction.

(44) Hans braucht ein Taschentuch.

Hans needs/uses a hanky

\footnotetext{
13 Such alternatives would lead to a violation of the presuppositions of SCALE; I leave it to the reader to go through the relevant computations. Note that my characterization for escort auch nur includes this requirement on ALT.
} 
(45) Es braucht etwas Vorsicht.

it needs some care

(impersonal) 'Some care has to be applied.'

(46) Es braucht nicht zu regnen.

it needs not to rain

'No rain is needed.'

(47) Frauen brauchen keine höhere Bildung zu haben.

impersonal deontic obligation: 'It is not necessary that women receive higher education.'

instantiated deontic obligation: 'There is no obligation for women to receive higher education.'

I therefore submit that scalar constructions never played a role in the development or licensing of brauchen 'must' as a polarity sensitive item.

Interestingly, the distributional patterns of brauchen in the 'must' sense are likewise not in line with any of the traditional NPI patterns. I will list some observations. The first examples confirm that negation words (nobody, never, no) all license brauchen, no matter whether the two words are adjacent or not.

(48) Niemand hier braucht Angst zu haben. nobody here needs fear to have 'nobody here needs to be afraid.' 
(49) Hans brauchte nie selber zu kochen.

Hans needed never himself to cook

'Hans never needed to cook by himself.'

Like other weak NPIs, brauchen can also be used in the scope of only.

(50) Hans braucht nur eine Frage zu beantworten.

Hans needs only one question to answer

'Hans only needs to answer one question.'

(51) Maria braucht bloss zu lächeln,dann freuen sich Maria needs only to smile, then rejoice themselves schon alle.

already all

'Mary only needs to smile and everyone is happy.'

Yet, brauchen ('must') is excluded from other contexts that license weak NPIs. Relevant sentences (brauchen in weak licensing contexts) are not barely mildly marked (as those we saw in Section 4) but simply incomprehensible, as several informants agreed.

(52) *Jeder, der eine Frage zu beantworten braucht, sieht everyone who a question to answer 'braucht', sees 
in ein Lexikon.

into an encyclopedia

intended: 'Everybody who has to answer a question checks in an encyclopedia.'

(53) *Wenn Du zu kochen brauchst, sollte ein Kochbuch If you to cook 'brauchst', shoulda cookbook da sein

there be

intended: 'If you have to cook, a cookbook should be available.'

(54) *Hans ist der größte Junge, den die Ärztin je zu Hans is the tallest boy, who the doctor ever to impfen brauchte.

vaccinate 'brauchte'

intended: 'Hans is the tallest boy the doctor ever had to vaccinate.’

(55) *Wenige Kinder brauchen zu kommen.

few children 'brauchen' to come

intended: 'Few children need to come.' 14

\footnotetext{
14 The data for wenige are intricate. An impersonal obligation construction in the sense of 'We only need few kids to be present' is possible, probably due to licensing by only. What is not available, though, is a reading in the sense of 'Few children are such: they must come'.
} 
The NPI brauchen ('must') hence confirms the hypothesis that negative polarity items with a history which does not refer to the $\mathrm{ALT}+\mathrm{SCALE}$ construction are in danger to be used in non-canonical distributional patterns. Here, the licensing contexts are somewhere between weak and strong NPIs.

Other items that are classed as NPIs and lack the potential to enter into scalar constructions (in German) are expressions like (nicht) in die Tüte kommen ('does not enter my bag'), (nicht) lange fackeln (lit. 'take a long time torching around'), einen Blumentopf gewinnen ('win a pot of flowers'). These can co-occur with nicht and negation quantifiers, but practically all other contexts are out. I illustrate a few good and bad contexts for fackeln.

(56) Er hat nicht lange gefackelt, und alle rausgeworfen. he has not long torched, and all thrown-out 'He did not hesitate long and threw them all out.'

(57) *Wenige haben lange gefackelt und ... few have long torched and ... *Nur Tom hat lang gefackelt ... only Tom has long torched ...

These items can show the distribution of strong NPIs which is simpler to spot and implement ('in the immediate scope of negation') than downward entailing contexts. They can also be limited more narrowly, or 
show irregular distributions like brauchen before. Like brauchen, there are no reasonable alternatives on the basis of which these expressions could enter an ALT+SCALE construction.

\section{Summary}

The first part of the paper was devoted to polarity sensitive items that could be called "well-behaved". We have a good understanding of pragmatic processes that give rise to the restrictions that such well-behaved NPIs observe: these are the ingredients and logical requirements imposed by ALT and SCALE. The usefulness of an analysis of NPIs in pragmatic terms is also confirmed in that we saw the same pragmatic ingredients reappear in many descendant words that can develop out of NPIs. Specifically, the potential to give rise to alternatives ALT is typical of several descendant items, even though the newly emerged words make use of the alternatives in new and different ways. From a historical perspective, we would also expect that non-pragmatic licensing mechanisms exist, taking over where the obligation to observe presuppositions gets weakened. Such non-pragmatic licensing mechanisms can single out a simpler range of contexts (e.g. ccommand by negation).

In the second part of the paper, I listed three types of negative polarity items which are not simply minimizers: scalar particles, NPIs which 
adopt a scalable meaning by analogy, and words that I called mimicry NPIs. These include German brauchen ('must') and other strong NPIs; due to their meaning, they do not have the potential to enter into an ALT+SCALE construction. I proposed that if a negative polarity items shows a nonstandard or simple distribution, then it might be because it does not have, and never had, the potential to be used in an ALT+SCALE construction.

\section{References}

Chierchia, Gennaro. 2004. Scalar implicatures, polarity phenomena, and the syntax/pragmatics interface. In Structure and Beyond: The Cartography of Syntactic Structures, vol. 3, Adriana Belletti (ed), 39103. Oxford: Oxford University Press.

Chierchia, Gennaro. 2006. Broaden your views. Implicatures of domain widening, and the 'logicality' of language. Linguistic Inquiry 37: 535590.

Condoravdi, Cleo. 2005. Not knowing or caring who. Extended handout presented at the Workshop on Context and Content, MIT/Harvard, July $2005,<$ http://www-csli.stanford.edu/ cleoc/AC/fc-han.pdf $>$ (last accessed June 10, 2011)

Dayal, Veneeta. 1998. Any as inherent modal. Linguistics and Philosophy 21: 433-476. 
Eckardt, Regine. 2003. Eine Runde im Jespersen-Zyklus: Negation, emphatische Negation, negative-polare Elemente im Altfranzösischen. KOPS. $<$ http://www.ub.uni-konstanz.de/kops/volltexte/2003/991>

Eckardt, Regine. 2005. Too poor to mention: subminimal events and negative polarity items. In Event Arguments in Syntax, Semantics and Discourse, Angelika Wöllstein-Leisten \& Claudia Maienborn (eds), 301-330. Tübingen: Niemeyer.

Eckardt, Regine. 2006. Meaning Change in Grammaticalization. An Enquiry into Semantic Reanalysis. Oxford: Oxford University Press.

Eckardt, Regine. 2008a. Even in Horn space. In Proceedings of the 2007 Tbilisi Symposium on Logic and Language, Peter Bosch, David Gabelaia \& Jerome Lang (eds), 47 - 62. Berlin \& New York: Springer Lecture Notes.

Eckardt, Regine. 2008b. The lower end of event ontology. In Event Structures in Form and Interpretation, Johannes Dölling, Tanja Heyde-Zybatov \& Martin Schäfer (eds), 477-492. Berlin: Walter de Gruyter.

Falaus, Anamaria. forthcoming. The importance of being small. An implicature-based approach to epistemic indefinites. Paper presented at SALT 20 (2010).

Fauconnier, Gilles. 1975. Pragmatic scales and logical structures. Linguistic Inquiry 6: 353-375. 
Giannakidou, Anastasia. 2001. The meaning of free choice. Linguistics and Philosophy 24: 659-735.

Guerzoni, Elena. 2004. Even-NPIs in yes-no questions. In Natural Language Semantics 12: 319-343.

Guerzoni, Elena. 2006. Intervention effects on NPIs and feature movement. Natural Language Semantics 14: 359-398.

Haspelmath, Martin. 1995. Diachronic sources of all and every. In Quantification in Natural Languages, vol. 2, Elke Bach, E. Jelinek, A. Kratzer \& Barbara Partee (eds), 373-382. Dordrecht: Kluwer.

Heim, Irene. 1984. A note on negative polarity and downward entailingness. In Proceedings of NELS 14, C. Jones \& P. Sells (eds), 98-107. Amherst: GLSA.

Hoeksema, Jack. 2002. Minimaliseerders in het standaard Nederlands. In: Tabu 32(3/4): 105 - 174.

Hoeksema, Jack. 2010a. Dutch ENIG: from nonveridicality to downward entailment. Natural Language and Linguistic Theory 28(4): 837 - 859. Hoeksema, Jack. 2010b. Negative and Positive Polarity Items: An investigation of the Interplay of Lexical Menaing and Global Conditions on Expression. In: Laurence Horn (ed.), The expressions of Negation. Berlin: Mouton deGruyter: 187 - 224.

Horn, Laurence R. 2000. Pick a theory (not just ANY theory). Indiscriminatives and the free-choice indefinite. In Negation and 
Polarity: Syntactic and Semantic Perspectives, Laurence R. Horn \& Yasuhiko Kato (eds), 147 - 192. Oxford: Oxford University Press.

Huddleston, Rodney \& Geoffrey L. Pullum. 2002. The Cambridge

Grammar of the English Language. Cambridge: Cambridge

University Press.

Israel, Michael. 1996. Polarity sensitivity as lexical semantics. Linguistics and Philosophy 19: 619-666.

Jäger, Agnes. 2008 [2006]. The History of German Negation. Amsterdam: John Benjamins.

Jayez, Jacques \& Lucia Tovena. 2003. Free choiceness and nonindividuation. Linguistics and Philosophy 28: 1-71.

Kadmon, Nirit, \& Fred Landman. 1993. Any. Linguistics and Philosophy 15: $353-422$.

König, Ekkehard. 1977. Form und Funktion. Tübingen: Niemeyer.

König, Ekkehard \& Elizabeth Closs Traugott. 1988. Pragmatic strengthening and semantic change: the conventionalizing of conversational implicature. In Understanding the Lexicon: Meaning, Sense and World Knowledge in Lexical Semantics, Werner Hüllen \& Rainer Schulze (eds), 110 - 124. Tübingen: Niemeyer.

Krifka, Manfred. 1995. The semantics and pragmatics of polarity items. Linguistic Analysis 25: 209-257.

Ladusaw, William A. 1979. Polarity Sensitivity as Inherent Scope Relations. $\mathrm{PhD}$ dissertation, University of Texas. [published as: Ladusaw, 
William A. 1980. Polarity Sensitivity as Inherent Scope Relations.

New York: Garland.]

Linebarger, M. 1987. Negative polarity and grammatical representation.

Linguistics and Philosophy 10: 325-387.

Menendez-Benito, Paula. Forthcoming. Universal free choice items in

Greek and Spanish. In Proceedings of the Workshop on Greek Syntax and Semantics, MIT, May 2007.

Menendez-Benito, Paula. 2006. Exclusive choices. In Proceedings of the 36th meeting of the North East Linguistic Society, Christopher Davis, Amy Rose Deal \& Youri Zabbal (eds), 467-480. Amherst: GLSA. Pereltsvaig, Asya. 2006. Negative polarity items in Russian and the 'bagel Problem'. In Negation in Slavic, Sue Brown \& Adam Przepiorkowski (eds), 153 - 178. Bloomington: Slavica Publishers.

van der Auwera, Johan. 2010. On the diachrony of negation. In Expressing

Negation, Larry Horn (ed), 73-109. Berlin: Mouton de Gruyter.

van der Wal, Sjoukje. 1996. Negative polarity items in English and Dutch: a lexical puzzle. Technical report, University of Groningen.

von Fintel, Kai 1999, NPI-licensing, Strawson-entailment, and contextdependency. Journal of Semantics 16: 97-148.

von der Gabelentz, Georg. 1901[1969]. Die Sprachwissenschaft. Ihre Aufgaben, Methoden und bisherigen Ergebnisse. Ed. by G. Narr, U. Petersen. Tübingen: Gunter Narr Verlag. 
Zeijlstra, Hedde. 2007. Negation in Natural Language. Language and Linguistics Compass 1: 498-518.

Zwarts, Frans. 1998. Three types of polarity. In Plurality and

Quantification, Fritz Hamm \& Erhard Hinrichs (eds), 177-228.

Dordrecht: Kluwer. 
Table 1. Traditional careers of NPIs

\begin{tabular}{|c|c|c|}
\hline denotation & $\begin{array}{l}\text { lexical } \\
\text { requirements }\end{array}$ & result \\
\hline $\mathrm{A}_{1}$ & none & $\begin{array}{l}\text { neutral word/expression; can } \\
\text { independently enter in ALT+SCALE } \\
\text { constructions }\end{array}$ \\
\hline $\begin{array}{l}\mathrm{A}_{2}: \\
\text { Generalization } \\
\text { from } \mathrm{A}_{1}\end{array}$ & $\begin{array}{l}\text { gives rise to ALT } \\
\text { needs SCALE }\end{array}$ & $\begin{array}{l}\text { (scalar) negative polarity item } \\
\text { (strong or weak) }\end{array}$ \\
\hline $\begin{array}{l}\mathrm{A}_{3} \text { : Bleaching } \\
\text { of } \mathrm{A}_{2}\end{array}$ & $\begin{array}{l}\text { ALT, SCALE lost } \\
\text { syntactic licensing }\end{array}$ & $\begin{array}{l}\text { indicates negative concord, presence } \\
\text { of negation }\end{array}$ \\
\hline $\begin{array}{l}\mathrm{A}_{4}: \mathrm{By} \\
\text { reanalysis } \\
\text { from } \mathrm{A}_{3} \\
\text { denotes } \neg \\
\end{array}$ & loss of licensing & negation \\
\hline $\begin{array}{l}\mathrm{A}_{5}: \text { Subjecti- } \\
\text { fication of } \\
\text { indefinite } \mathrm{A}_{2}\end{array}$ & $\begin{array}{l}\text { gives rise to ALT } \\
\text { epistemic } \\
\text { discharge }\end{array}$ & epistemic indefinites \\
\hline $\begin{array}{l}\mathrm{A}_{6}: \text { By reana- } \\
\text { lysis from } \\
\text { indefinite } \mathrm{A}_{2} \text {; } \\
\text { denotes } \forall\end{array}$ & $\begin{array}{l}\text { gives rise to ALT } \\
\text { free choice dis- } \\
\text { charge }\end{array}$ & free choice items \\
\hline $\begin{array}{l}\mathrm{A}_{7} \text { : By } \\
\text { bleaching from } \\
\mathrm{A}_{6} \\
\text { denotes } \forall\end{array}$ & none & neutral universal quantifier \\
\hline
\end{tabular}


